The following article was published in the February 2005 issue of Mental Retardation, volume 43, number 1: 43-47.

\title{
Problems Associated With Use of Physical and Mechanical Restraints in Contemporary Human Services
}

\section{Marc Tumeinski}

The use of restraint techniques in contemporary human services is endemic and in some fields is growing. Although I will define restraint more explicitly below, basically, human service restraint is the use of force by service workers to limit the movement of human service clients. Ironically, the analysis of and approaches to this problem for the most part remain relatively elementary and sometimes even superficial and, therefore, are of limited effectiveness. Considering the physical and psychological dangers associated with restraint as well as the seriousness of the decision to use force on another human being, there has been little in-depth critical examination of the issue. Although some individuals and organizations have raised concerns and taken strong positions against restraint, even these have mostly focused attention on abuses and excesses rather than on the inherent nature of restraint use.

An example of such simplistic analysis is illustrated by the reality that restraint use is typically addressed in services as a stand-alone issue (e.g., it is all about the person restrained), when, in actuality, many things directly or indirectly impact on it. This reality is often not considered when use of restraint is discussed; or, if it is addressed, it is often done so only in a shallow fashion. Influences from different realms, such as the society, family, government, law, economy, politics, and human service agencies, impact on restraint use. Some examples from these realms include societal stereotypes about the people served, the incidence of violence in a society, budget decisions about human service funding, agency mindset, agency staffing patterns, backgrounds and personality of staff, and so on. In general, the majority of contemporary advocacy organizations, services, and service workers view restraint as an effective and sometimes necessary, albeit somewhat regrettable, tool in service practice.

What is restraint? Restraint is the use of force to limit another person's movement. It commonly takes one or more of three forms: (a) physical (so-called "holds"), (b) mechanical (the use of mechanical devices such as straps), and (c) chemical (the use of drugs, either one-time or long-term). 
In this article, I limit my discussion primarily, but not exclusively, to human service use of physical and mechanical restraints, mainly because the use of chemical restraints is such a complex issue that it raises a whole host of related issues (see Wolfensberger, 1994), which would make it unmanageable given the intended length of this article. However, readers should note that many of the points raised will have a bearing on the use of chemical restraints in human services. They should also note that this article is concerned specifically with the use of restraints in formal, organized, and agency-based human services and less with what families or friends may do in providing informal service and help. Finally, I have geared this article to mental retardation services, but many of the points are applicable to restraint use in different human service fields.

A variety of service fields (e. g., residential, educational, medical, work, and day programs) and service workers (e.g., direct care, teachers, nurses, doctors, aides) use restraint techniques. They are used on people with a range of socially devalued conditions (e.g., mental retardation, mental disorder, "behavioral" labels, homelessness/ poverty) of all ages (from children to elders).

Restraints used, taught, and mandated by human services agencies, programs, and systems can be distinguished from personal, informal and ad hoc efforts, such as a parent stopping a child from running into the street or a friend stopping another friend from getting into a fist fight. Devices used for a legitimate medical purpose (e. g. , to assist someone in body positioning) are also not restraints as defined above.

In mental retardation services where restraints are used, most human service professionals today tend to be more preoccupied with managing restraints "safely" or with deciding when they are and are not "appropriate" than with addressing the question of whether using them is valid in the first place. Part of this trend is often due to their human service training, or lack thereof. Not enough thought is given to, for example, the human costs of using restraint, the question of whether it really "works," what it does to the restrained person, or how it affects the relationship between the "restrainer" and the "restrained."

Perhaps surprisingly to some readers, this is not a new issue in human services. Similar questions on the use of restraints were raised, for example, during the period of the 'moral treatment' movement in parts of Europe and the United States in the 18th and 19th centuries. Most contemporary human service workers, particularly those involved with restraint, would find it instructive to study the ideology, history, and successes of the moral treatment movement, which largely rejected the contemporary practices of mechanical restraint (see Bockoven, 1963; a one-page 
description of Wolfensberger's "Moral Treatment" workshop entitled "The 19th Century 'Moral Treatment' Approach to Human Services, Especially to the Treatment of Mental Disorder, \& Lessons for Services of Our Own Day").

For the most part, the human service field has couched the issue of restraint use in a narrow rights perspective that tends to cloud the deeper issues. The prevailing thinking in services is that the use of restraints falls primarily within the domain of human rights as defined by public policy; in other words, that it is about "balancing" the rights of the restrained person with the rights of others. A rights perspective can have some utility in certain circumstances, but it is an insufficient basis for dealing with the complexity of the issue of restraint use.

Much as we would like to think that the same rights are equally granted to all people, in practice rights are rooted in the value that a person is afforded or may lay claim to in society. The problem is that when a person's social value is denied or diminished, then any rights dependent on that value will in turn be denied or curtailed. People who are restrained by services -- including people with mental retardation -- are almost always highly vulnerable, deeply socially devalued, and very "wounded" people (see Vanier, 1992; Wolfensberger, 2000a); often made so at least in part by the very services they receive. In short, their value in the eyes of society is diminished or denied, and consequently their rights are often typically abridged.

This is one of the reasons why contemporary services, including those provided to people who are mentally retarded, seem to be so preoccupied with "rights" -because many of the rights of people with mental retardation who are clients of human service organizations are so often denied, ignored or limited by society. This is true, and it is a problem for many socially devalued people. Paradoxically, however, a strictly rights-based response to this problem offers little or no protection, particularly in the long run, to someone who is socially devalued and mentally retarded (see Wolfensberger, 1997a; two handouts from Wolfensberger's "Rights" workshop with headings "Problems With the Current 'Rights' Discourse in Social Advocacy \& Human Service Circles" and "6 Realities Associated With Human Law That Also Reveal its Limitations \& Shortfalls").

Indeed, a strictly rights-based approach to the use of restraint by human services may allow or cause harm to service recipients (e.g., when people who are socially devalued and mentally retarded have been restrained by their services and have suffered physical and/ or psychological harm as a result, the agency-stated rationale is often that the restraint was a legitimate abridgment of the person's rights or was 
done to protect the rights of others. This is commonly a simplistic explanation of a much more complex human issue.)

Another deeper issue, though, is that something more important than rights is at stake. On a fundamental level, human service restraint use is much more of a moral issue than a rights issue. When I describe human service restraint use as a moral issue, I mean that it raises questions of right and wrong and that it has moral implications for everyone involved. Using the term moral does not automatically imply that the use of restraints by human services is immoral: first, one recognizes it as a moral issue; second, one determines the nature of its moral quality (i.e., moral or immoral); and third, one strives as much as possible to do what is morally correct. I am not attempting in such a brief article to prescribe what service workers (or family members) should do, but I am urgently encouraging them to undertake a process of moral discernment and rational analysis of an issue that clearly affects the lives of people with mental retardation.

If what I propose is true, that the use of restraints in human services is fundamentally a moral issue, then service workers at all levels of agency responsibility would do well to deal with it first and most fundamentally on the level of right and wrong. Only then would a rights perspective (as well as other perspectives) on restraint use have some measure of relevance to, and effectiveness in, addressing the fundamental and pressing needs of children and adults who have mental retardation and are being restrained by services. Proponents of a rights perspective naturally tend to look at issues solely from the perspective of the affected person, whereas those who espouse a moral perspective would look at not only the restrained person, but also how restraint use affects their family, friends, advocates, service workers, fellow service clients, community, and even society. As long as services are less conscious of, unconscious of, or ignore the moral domain in relation to restraint use, this issue will never be resolved in accordance with the noble ideals of being involved in service to vulnerable people, including those with mental retardation.

Some of the signs which indicate that human service restraint use falls in the moral realm include (but are not limited to):

- the actual and potential degree of harm (physical, psychological, emotional, social) often done to children and adults, including those who are mentally retarded, as a result of their being restrained by human services; 
- the negative effect that human service restraint use commonly has on the user (e.g., creating confusion, guilt, regret, fear, "hardening" of their heart, meanness, enjoyment of power and control);

- the "slippery slope" phenomenon often associated with moral issues (e.g., the use of restraints once started tends to increase not decrease; once started it tends to be used on more and more people in more and more situations; and it often opens the door to other controlling and aversive techniques being used);

- the high degree to which human service restraint use has been, and still is, often surrounded by deception, cover-ups, detoxified language, denial of harmdoing, concealing of economic motives for its use; and

- the significant damage that human service restraint use quite often causes to relationships (i.e., those between service workers and clients, between clients themselves). The use of restraints by a worker(s) on a service client often creates mutual mistrust, resentment, fear, anxiety, confusion, etc. The high use of restraints in services can cause some people with mental retardation and others who are socially devalued to take out their anger and frustration caused by their being restrained on other weaker service clients.

There are several all too common contemporary moral dilemmas raised by human service use of restraints on people with mental retardation. I will highlight just two of them. (By dilemma, I do not mean an academic problem, but a flesh and blood problem for real people.) One such moral dilemma is tied to the prevailing misconception that largely surrounds the use of restraints in mental retardation services; namely, that it is most often or even always used only in situations of personal danger to human service clients, family, staff, members of the public, or others. On the contrary, talking with people who have been restrained as well as with their families, or reading accounts of restraint use, will show that in the majority of instances when someone was injured or even killed as the result of a restraint, the initial situation was not one of danger, but rather of service staff members (even unconsciously) trying to control their clients to maintain the status quo and a smoothrunning program.

For those circumstances where the threat of violence against self or others is truly present, which are less frequent than commonly thought, more often than not they have been brought about by years, even decades, of wounding in the lives of devalued people, often caused by irrelevant, impotent, and inferior agency-based services (see Wolfensberger, 1992; one-page description of Wolfensberger's "Human Service 
Violence" workshop entitled "Overview of a 11 / 2 to 2-Day Presentation on the Sources \& Dynamics of Violence in Human Services, \& How to Minimize the Likelihood of Violence" and an untitled document listing the 13 topics covered in the aforementioned workshop). This does not minimize the painful reality of violence by human service clients, when it actually occurs, but rather underscores the moral nature of the problem.

Another moral dilemma is that as long as the majority of formal, organized, agency-based mental retardation service personnel consciously or unconsciously rely heavily on service models built on segregation, congregation, and control of service clients, then in our contemporary societal and human service environments, the odds are high that the use of physical and mechanical restraints will be seen as a valid, even desirable option. As long as this is the case, many families with intellectually impaired members will continue to be put in situations where they either accept the use of restraint by an agency/ agencies or try to support their family member without formal services. This is not a fair choice, partly because organized, agency-based services have often created and/ or exacerbated the problems in the first place (see McKnight, 1995) that have later led to restraints being offered as the "solution."

Some families have decided to try to support their child with no or very little agency-based services because of this problem. Some have decided to personally limit their son or daughter's movement, which still raises moral questions of course, but this is intrinsically different from human service use of restraint, as mentioned above.

This is an essential distinction to grasp. Some of the differences include, for example, that the nature of the parent's relationship is radically different than paid staff's relationship with the person and that the parents often take on hardship themselves when they do decide to limit their child's movement.

An example of such hardship that I am familiar with is two parents who slept in their bed with their young child between them to prevent him from hitting himself. They tied his hands gently to their hands, so that if he started hitting himself, they would wake and comfort him. This made it extremely difficult for either parent to get a good night's sleep, which was no small matter, given that they did this for years.

Another example of such hardship is parents who have decided to accept physical strikes from their child without hitting back, using human service restraint techniques, or punishing them in any way. Instead, such parents have typically relied on the normative patterns of familial life and child rearing, such as love, forgiveness, high expectations, shared celebrations and hardships, and help from extended family and other relationships. 
An example of a "non-retaliatory" and "non-restraint" stance taken by a service worker is described in chapter 6 of the book Enough Room for J oy (Clarke, 1974). Such an approach, particularly when one strives to not hold any grudges against or fears of the person, is a difficult ideal as well as an inspiring example of service. These are only examples, meant to illustrate what some families and others have done in some very difficult circumstances, often as a result of trying to undo or ameliorate the damage done to their family member through agency-based services, many of which used restraints. There is so much to study and learn about providing relevant and effective service to people who are mentally retarded and socially devalued (see Wolfensberger, 2000a).

In conclusion, if one does decide that the use of restraints in human services is fundamentally a moral issue, then it is essential that one at least:

- discern the most fundamental issues at stake;

- decide on what is right and what is wrong relative to this issue;

- acknowledge our limitations as human beings to always do what is morally correct;

- acknowledge our real limitations as human service workers, but also as human beings, to make positive change in the lives of wounded people;

- cultivate a spirit of humility in acknowledgment of the power one holds as a human service worker over the lives of service clients;

- acknowledge compromises, mistakes, and wrong doing;

- seek to make reparation and amends when necessary;

- accept the (moral) consequences of our actions; and

- strive for personal integrity on the issue; in other words, decide to say and to do what is right, regardless of what others say and, ideally, do so regardless even of the personal cost to oneself (see overhead from Wolfensberger's "Disfunctional (Human Service) World" workshop with heading " 5 Elements of an Act Validity Strategy").

\section{References}

Bockoven, J. S. (1963). Moral treatment in American psychiatry. New York: Springer. Clarke, B. (1974). Enough room for joy. Toronto: McClelland and Stewart.

McKnight, J . (1995). The careless society: Community and its counterfeits. New York: BasicBooks.

Vanier, J . (1992). From brokenness to community. New York: Paulist Press. Wolfensberger, W. (1992). The new genocide of handicapped and afflicted people (2nd ed., rev). Syracuse: Author. 
Wolfensberger, W. (1994). Reply to Levitas, McCandleless, Elenewski and Sobel. Syracuse: Syracuse University Training Institute for Human Service Planning, Leadership \& Change Agentry.

Wolfensberger, W. (1997a). Major obstacles to rationality and quality of human services in contemporary society. In R. Adams (Ed.), Crisis in the human services: National and international Issues: Selected Papers from a conference held at the University of Cambridge September 1996. Kingston upon Hull, UK: University of Lincolnshire and Humberside.

Wolfensberger, W. (1997b). Workshop on the 19th century 'moral treatment' approach to human services. Syracuse: Syracuse University Training Institute for Human Service Planning, Leadership \& Change Agentry.

Wolfensberger, W. (2000a). A brief overview of social role valorization. Mental Retardation, 38, 105-123.

Wolfensberger, W. (2000b). Workshop on a critical examination of the current concept of 'rights' in the contemporary culture of advocacy \& human services. Syracuse: Syracuse University Training Institute for Human Service Planning, Leadership \& Change Agentry.

Wolfensberger, W. (2002). Workshop on how to function morally, coherently \& adaptively in a disfunctional (human service) world. Syracuse: Syracuse University Training Institute for Human Service Planning, Leadership \& Change Agentry. Wolfensberger, W. (2004). Workshop on the sources and dynamics of violence in human services, and how to minimize the likelihood of such violence. Syracuse: Syracuse University Training Institute for Human Service Planning, Leadership \& Change Agentry.

I thank Dr. Wolf Wolfensberger for his unfailing and generous teaching and mentorship as well as for his inspiration and specific help with this article. For information on the Wolfensberger workshops or the Reply to Levitas et. al. article, contact the Training Coordinator of the Syracuse University Training Institute for Human Service Planning, Leadership \& Change Agentry, 800 S. Wilbur Ave., Suite 3B1, Syracuse, NY 13204.

\section{Author:}

Marc Tumeinski, BS, Training Coordinator, SRV Implementation Proj ect, 74 Elm St., Worcester, MA 01609. E-mail: info@srvip.org 